\title{
Gradhiva
}

GRADHIV

Revue d'anthropologie et d'histoire des arts

$7 \mid 2008$

Le possédé spectaculaire

\section{Les temples de la Mère Inde, musées de la nation}

The temples of "Mother India", museums of the nation

\section{Mathieu Claveyrolas}

\section{(2) OpenEdition}

Journals

Édition électronique

URL : http://journals.openedition.org/gradhiva/1075

DOI : 10.4000/gradhiva. 1075

ISSN : 1760-849X

Éditeur

Musée du quai Branly Jacques Chirac

Édition imprimée

Date de publication : 15 mai 2008

Pagination : 84-99

ISBN : 978-2-915133-86-8

ISSN : 0764-8928

Référence électronique

Mathieu Claveyrolas, « Les temples de la Mère Inde, musées de la nation », Gradhiva [En ligne], 7 |

2008, mis en ligne le 15 mai 2011, consulté le 10 décembre 2020. URL : http://

journals.openedition.org/gradhiva/1075; DOI : https://doi.org/10.4000/gradhiva.1075

(c) musée du quai Branly 


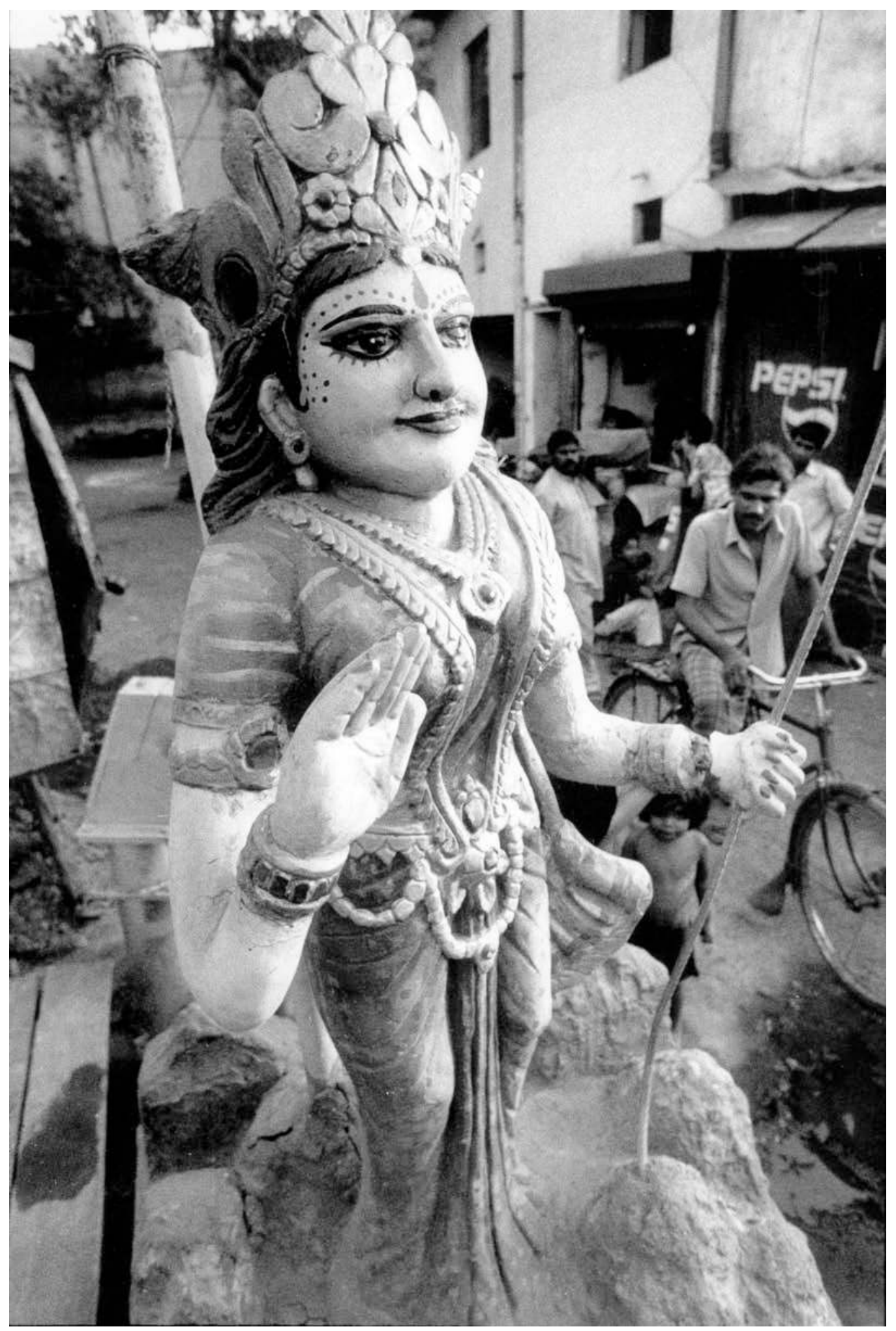

Fig. 1 Statue de Bharat Mata, la déesse de l'Inde Mère, dans un quartier ouvrier de Kanpur (Uttar Pradesh), mai 2008. Photo Nicolas Jaoul. 


\section{Les temples de la Mère Inde, musées de la nation}

\section{Mathieu Claveyrolas}

$\mathrm{I}$ l existe en Inde du Nord plusieurs temples dédiés à "Mère Inde », qui commémorent la nation indienne et proposent comme point fort de la visite une carte en relief du territoire indien. L'un des premiers temples de Mère Inde fut fondé à Bénarès et inauguré par Gandhi en 1936. Bénarès est l'un des lieux où le nationalisme hindou s'est institutionnalisé1. C'est aussi une ville phare de la religion hindoue et l'une des principales villes de pèlerinage, ce qui explique en partie sa dimension cosmopolite et sa relative représentativité sociologique : on y retrouve la plupart des communautés indiennes en termes d'origine géographique, de castes, de religions ou de langues. Bénarès revendique par ailleurs le statut de microcosme idéal du territoire sacré hindou'. Comment penser, dans ce contexte - celui d'une ville sainte prétendant représenter le territoire et le cosmos hindous-, la légitimité d'un temple explicitement dédié, à travers cette carte en relief, à la totalité du territoire indien?

On connaît les possibles rapprochements entre lieu saint et musée ${ }^{3}$ : outre le respect et l'admiration consensuels qu'ils suscitent l'un et l'autre, la vocation pédagogique des musées n'exclut pas une scénographie sacralisant les objets et les cultures dont ils se font parfois le « sanctuaire ». De même, la mise en scène du divin dont témoignent certains lieux saints relève en partie d'une pédagogie visant à l'édification du dévot.
En Inde, les visites de temples-musées sont, aujourd'hui, les jalons obligés du pèlerinage hindout. Les temples de Mère Inde illustrent plusieurs articulations possibles de ces deux statuts - temple et musée - et, parallèlement, l'évolution de l'Inde du nationalisme séculier vers le nationalisme religieux. Le temple de Bénarès auquel cet article est consacrés laisse de surcroît la porte ouverte à différentes interprétations. Il est particulièrement intéressant d'étudier les potentialités variées du lieu (musée à la nation séculière, temple de la nation hindoue), de

1. Avec, notamment, la fondation de la Banaras Hindu University (BHU) dès 1916.

2. Sa géographie sacrée inclut notamment l'ensemble des sites pèlerins hindous. Eck (1985: 45), Singh (1988) et Vidyarthi (1979), par exemple, reprennent à leur compte cette vision mythologique de Bénarès. Il convient pourtant de nuancer l'image d'un territoire unique et exemplaire, et de lui préférer la vision de Bénarès comme un centre parmi d'autres du réseau de territoires hindous (Bakker 1996 : 32 ; Eck 1998).

3. Voir par exemple Rivière et Leroux-Dhuys (1991) pour les fondements historiques de cette comparaison, et Galinier et Molinié (1998] ainsi que Claveyrolas (2006) pour des exemples contemporains.

4. À Bénarès, par exemple, le temple Tulsimanas expose des tableaux d'automates figurant les passages clés de l'épopée du Ramayana.

5. Cet article est le résultat de plusieurs terrains à Bénarès, notamment en octobre-novembre 2003 et en janvier-février 2006. Je remercie Sanjay et Hariram Singh, qui facilitèrent l'enquête, ainsi que Catherine Clémentin-0jha, Frédérique Pagani et Gilles Tarabout, qui ont bien voulu le relire et en critiquer les versions intermédiaires. 




Fig. 2 Groupe de pèlerins sur les bords du Gange. Bénarès, 2006. Photo Mathieu Claveyrolas (M. C.)

discuter celles qui s'y sont réalisées ainsi que l'évolution du statut du temple-musée au gré, surtout, de manipulations idéologiques et de relectures de l'histoire indienne. L'ambition de cet article n'est pas cependant de théoriser le nationalisme indien et hindou, mais plutôt de contribuer à ce débat à partir de deux approches décalées qui me semblent importantes : d'une part, en s'attachant à un cas ethnographique précis et, d'autre part, en évaluant le temple concerné du point de vue de sa pertinence et de son efficacité religieuse autant que politique.

\section{Les modèles du temple et du pèlerinage}

Fondé voilà soixante-dix ans, le temple de Mère Inde de Bénarès est situé dans la partie nord du territoire sacré de Kashi (appellation mythologique de Bénarès). Le visiteur, touriste ou pèlerin (rarement banarsi), est accueilli par une banderole frappée du nom « Bharat Mata mandir » (littéralement : « temple de Mère Inde »). Il pénètre donc bien dans un «temple» (mandir). D'ailleurs, le bâtiment est entouré d'un parc de verdure, appelé seva apavan («jardin du service »). Cette appellation renvoie à une organisation religieuse de l'espace, en référence à la forêt (van), territoire des renonçants et des ermitages qui, dans les représentations hindoues classiques, enserre le village et son centre, le lieu de culte $^{6}$. Comme à l'entrée d'autres lieux saints, le visiteur laisse ses chaussures à un gardien au pied de quelques marches qui mènent à une plateforme. De là, il passe sous une galerie couverte (mandapa), élément également commun aux lieux de culte hindous, le conduisant à l'intérieur du temple.

L'intérieur est constitué d'une seule pièce carrée d'une vingtaine de mètres de côté dont le centre et l'essentiel de la surface au sol sont occupés par une carte de l'Inde en marbre. Les visiteurs, comme les responsables du temple, parlent de «la carte [map, mancitr] de l'Inde », mais surtout de Mère Inde. Cette divinisation du territoire indien, et de la patrie indienne, a récemment pris la forme d'une déesse, Bharat Mata, fortement anthropomorphe et rattachée, du point de vue du panthéon hindou, à la déesse Durga (toutes deux ont le tigre - ou le lion-pour monture7).

6. Pour une discussion du rôle de la forêt dans l'organisation spatiale d'un temple banarsi, voir Claveyrolas 2003 : 364 et suiv.

7. Si les nationalistes hindous insistent sur cette assimilation à la déesse Durga, l'iconographie la plus répandue présente pourtant Bharat Mata avec deux bras (Durga en a quatre ou huit) et tenant le drapeau national indien (ou celui du parti du Congrès) en lieu et place du trident de Durga. Sur l'usage nationaliste de l'iconographie hindoue, lire par exemple Pinney 2004 et Ramaswamy 2003. 


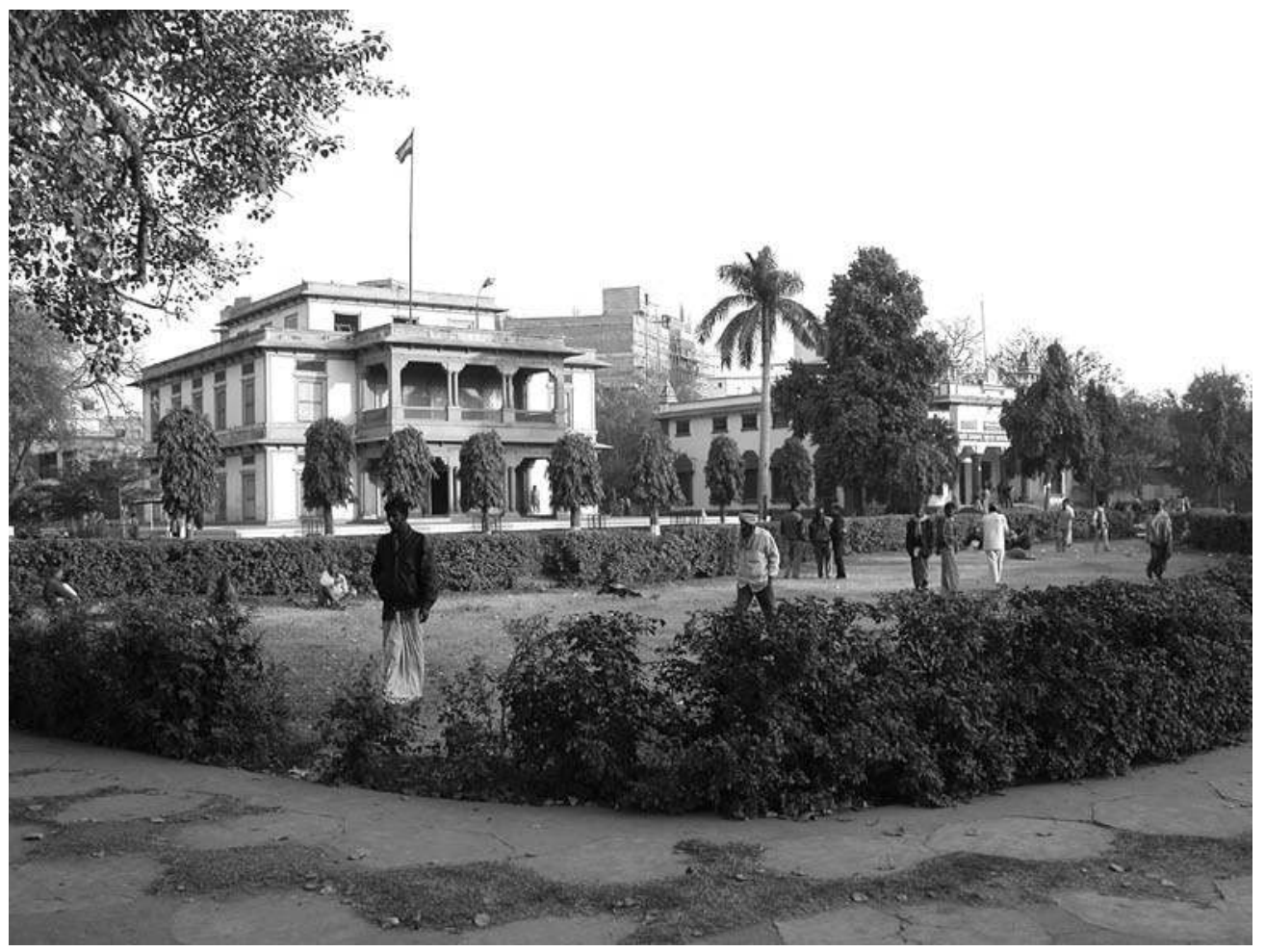

Fig. 3 Vue générale du temple et du jardin qui l'entoure, 2006. Photo M. C.

Le visiteur regarde en contrebas la carte en relief, qui représente moins les frontières politiques de l'Inde que l'Asie du Sud dans un sens très large : de l'Afghanistan à l'extrémité ouest de Sumatra, et des Maldives au sudouest de la Chine. Il fait le tour de la carte le long d'une galerie décorée de photographies et de chromos des principaux héros de l'histoire indienne contemporaine (quasi exclusivement ceux liés à la lutte pour l'indépendance ${ }^{8}$ ). Il s'arrête souvent et tente de déchiffrer les nombreuses reproductions du chant national, Vande mataram, et les cartes de l'Inde et du système solaire, en grande partie effacées.

"C'est un temple moderne, mais c'est un temple comme les autres. Chaque temple a sa spécificité. Lui, c'est cette carte. C'est cette carte qui fait que le temple attire tant de touristes. "Vir Bhadra Mishra, mahant (administrateur religieux) d'un des principaux temples de Bénarès, ne dénie pas au temple Bharat Mata le statut de lieu saint. Tout juste regrette-t-il la tendance globale qu'il incarne à ses yeux, consistant pour le dévot hindou à être spectateur ("touriste") de sa propre relation au divin : "Venir à Bénarès est déjà un acte de dévotion envers Mère Inde, mais les choses ont changé et les gens ont besoin de cette mise en scène. »
Mon principal interlocuteur au temple Bharat Mata fut le prêtre gardien Hariram Singh. Selon ses premiers discours, le temple proposerait l'expérience pèlerine de la totalité de l'univers indien : «Prendre la vision de Bharat Mata, c'est faire le tour de l'Inde. Et voyager en Inde, c'est faire un pèlerinage puisque la terre est sacrée. » Comparer ainsi le pèlerinage traditionnel et la visite du temple est un discours particulièrement évocateur dans le monde hindou, et a fortiori à Bénarès, ce microcosme hindou idéal.

Le territoire autour duquel déambule le pèlerin hindou est, symboliquement, celui du cosmos, dont l'Inde figure le centre. C'est la signification du « Grand Pèlerinage " mis en scène dans le Mahabharata tel qu'analysé par Bhardwaj (1973 : 44). L'auteur précise : « Le voyage sacré (yatra) suit grossièrement la direction du soleil, en englobant virtuellement la totalité $\mathrm{du}$ sous-continent indien [...]. En effet, ce Grand

8. On reconnaît Vivekananda, réformateur hindou, Rajendra Prasad, premier président de l'Inde, Bankim Chandra Chatterji, auteur du chant national, Subhas Chandra Bose, leader de l'Indian National Army, en uniforme militaire, Bhagat Singh, déguisé en Occidental, prenant la fuite après avoir tué un policier britannique, Chandra Shekhar Azad, avec son pistolet, Sardar Patel, Lal Bahadur Shastri, Indira Gandhi, Gandhi, Nehru et Madan Mohan Malaviya. 
Pèlerinage n'était pas seulement un long voyage sacré en Inde, mais aussi une circumambulation de l'axe cosmique hindou » (Bhardwaj 1999). Dans le monde hindou, le foisonnement des représentations du divin favorise la multiplication des substituts 9 . Certaines formes plus récentes de pèlerinage englobent ainsi à leur tour symboliquement l'ensemble du cosmos, représenté par le territoire indien. Citons notamment le pèlerinage aux quatre villes saintes (et les très nombreuses variantes proposées par les agences spécialisées), représentant les quatre directions cardinales. Le pèlerin hindou recherche l'expérience d'un univers total que lui offre le territoire indien en tant que réseau de lieux saints. Faut-il voir un substitut de ce pèlerinage idéal dans la déambulation autour de la carte du temple Bharat Mata?

Mise en scène pour pèlerin touriste ou raccourcisubstitut du pèlerinage autour du territoire sacré, la carte de l'Inde présentée au temple Bharat Mata serait donc en un sens assimilable à une image divine, et sa "vision " (darshan, soit l'échange de regards entre dieux et dévots qui est au centre de la pratique dévotionnelle dans les temples) à un pèlerinage.

\section{Ni officiant, ni image divine, ni dieu}

Le lieu saint hindou construit habituellement sa légitimité (son statut extra-ordinaire et efficace) par opposition à l'espace et à la temporalité extérieurs, en revendiquant un espace-temps éternel et préservé. Ici, au contraire, l'insistance sur les liens avec l'Indépendance nationale tend à inscrire le temple Bharat Mata dans l'Histoire, ce temps extérieur au temple car non éternel, non mythique. Et la représentation cartographiée $\mathrm{du}$ territoire indien réintroduit dans le saint des saints l'espace extérieur. Pourtant, le modèle du temple reste ici pertinent dans la mesure où la construction de l'identité nationale indienne à partir de matériaux historiques et géographiques s'apparente à l'élaboration d'un mythe à forte résonance religieuse.

D'un point de vue plus formel, le modèle du temple n'est plus justifié. En effet, il n'y a pas de responsable rituel. Hariram Singh ${ }^{10}$ est parfois appelé pujari (officiant de temple), mais le terme lui semble peu approprié: « Je ne suis pas pujari parce qu'il n'y a pas de culte [puja], pas d'image divine [murti]. C'est un temple moderne [modern temple en anglais]. " Sa charge consiste, selon les termes de son fils également employé du temple, à « ouvrir, fermer et nettoyer le temple ». Laver la carte au jet ne renvoie à aucune onction rituelle.
Comble de l'irrespect et de la transmission de l'impureté en contexte hindou, Hariram Singh marche même sur la carte pour en atteindre les recoins les plus difficiles d'accès. C'est également le cas des guides pour pèlerins, qui ne disposent pas de laser pour montrer les parties de la carte qu'ils commentent. En outre, la localisation de la carte en contrebas, accentuée par la possibilité de l'admirer d'en haut en montant à l'étage, contraste avec le soin porté par les hindous à toujours élever l'image divine, quitte à la poser sur un socle ou une plateforme.

Pas d'officiant rituel et pas d'image divine, donc, d'après Hariram Singh, qui infléchit son discours au fur et à mesure de nos discussions : " Aucun Indien ne vient là pour rendre sa dévotion. » L'ambiguité statutaire du lieu resurgit lorsqu'il précise : «Ils viennent pour rendre leur dévotion mais ils ne le peuvent pas. Sans image divine, il ne peut pas y avoir de sentiment dévotionnel. [Ce temple] n'a pas été construit pour la dévotion mais pour créer un sentiment de nationalisme, pour le respect à la Nation. » Le responsable va même plus loin, ajoutant à l'absence d'image divine et d'officiant rituel celle de dieu : « Le temple a été fondé sur d'autres bases que la mythologie ${ }^{11}$. Sur les trois millions trois cent mille dieux de la mythologie hindoue, il n'existe pas de déesse Bharat Mata. " L'attente créée chez le visiteur par la dénomination de " temple ${ }^{12}$ » et par certaines caractéristiques physiques et symboliques du lieu serait donc nécessairement déçue, transformant le pèlerin en visiteur d'un musée voué à l'histoire de l'Indépendance indienne.

De fait, le lieu se veut autre chose qu'un temple. Les légendes de fondation constituent très souvent la première information offerte à l'ethnologue par les acteurs d'un lieu saint. D'une part, elles légitiment à leurs yeux le statut du temple et du dieu auquel il est dédié; d'autre part, elles sont une mine d'informations pour

9. Il existe d'ailleurs à Bénarès un temple, Panchakroshi, conçu comme une réplique du territoire sacré de Bénarès et dont la circumambulation équivaut au pèlerinage (panchakroshi yatra) autour de la ville.

10. Originaire d'un village à une vingtaine de kilomètres de Bénarès, c'est un kshatriya (caste varna des « rois » ou « guerriers 》 traditionnellement écartés des activités rituelles, dévolues aux brahmanes].

11. On remarquera que Hariram Singh, pour parler du panthéon hindou, emploie le terme anglais mythology, qui appartient davantage au registre des sciences sociales qu'à celui du croyant et du responsable religieux.

12. Encore faut-il préciser que les nationalistes hindous ont étendu l'usage du terme mandir, notamment en baptisant leurs écoles Sarasvati shishu mandir, temple des élèves de Sarasvati (déesse de la Connaissance), ce qui introduit un doute sur l'attente réelle du pèlerin quant au statut du lieu qu'il visite. 


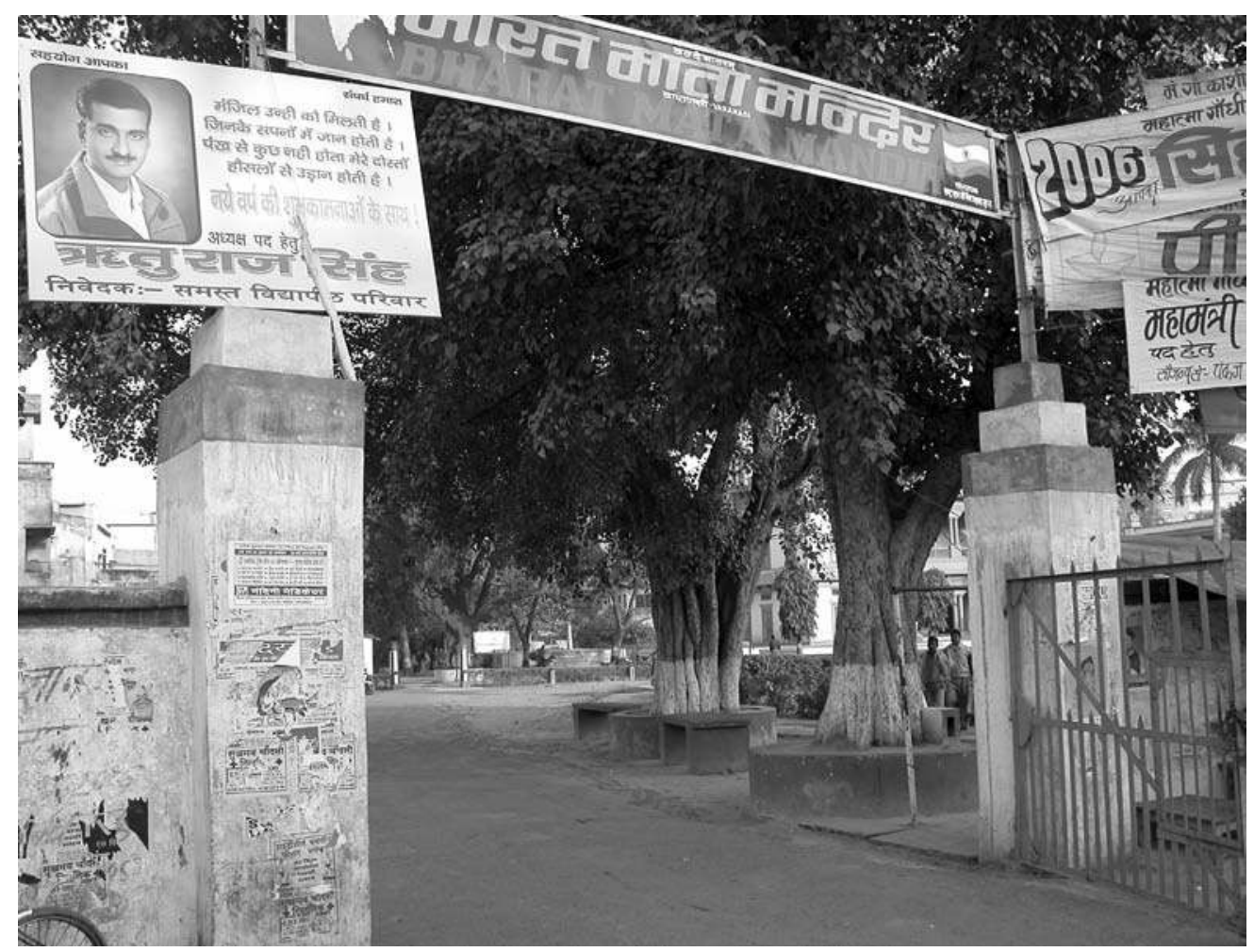

Fig.4 L'entrée du temple avec la banderole encadrée de la carte (à gauche, coupée) et du drapeau indien, 2006. Photo M. C.

l'ethnologue qui y lit l'inscription de la divinité locale dans un panthéon, et celle du temple dans un réseau social et dans un réseau de lieux saints. Hariram Singh explique pourtant qu'ici « il n'est pas important de connaître le récit de fondation. Il faut plutôt le background historique de la lutte nationaliste [pour l'indépendance] ». C'est donc bien d'une volonté d'inscription dans l'histoire qu'il s'agit (ou, du moins, dans une certaine perception de l'histoire).

Ici, en guise de récit fondateur, plusieurs livrets en vente au temple proposent, en hindi et en anglais, une présentation rapide de la carte, du temple et de son histoire. Le lecteur y apprend qu'il fut fondé en 1936 par Shiv Prasad Gupta, un proche de Gandhi. Distingué par sa lutte anti-britannique, cétait un membre important du parti du Congrès (Indian National Congress) qui, à cette époque, orchestrait la lutte anticoloniale. Son héritier demeure, aujourd'hui encore, l'un des hommes clés de Bénarès : il est même appelé "second maharaja $a^{13}$ " en écho, m'explique-t-on, à son statut de riche vaishya [caste des commerçants].

L'idée de fonder le temple Bharat Mata vint à Shiv Prasad Gupta en $1913^{14}$. De retour d'une session annuelle du parti du Congrès à Karachi, il visite à Pune une maison pour veuves de militants indépendantistes, où il voit pour la première fois une carte en relief de l'Inde faite en terre, respectant l'échelle et l'altitude. Le contexte fondateur est explicite : réunion du parti indépendantiste sous domination coloniale, référence aux veuves des martyrs de la lutte d'Indépendance, insistance sur l'exactitude topographique de la représentation du territoire. Remarquons en outre la mention du lieu de départ de ce récit fondateur : la ville de Karachi, aujourd'hui au Pakistan, symbole du démembrement initial de Mère Inde que fut la partition ${ }^{15}$.

Séduit, Shiv Prasad Gupta décide de bâtir une carte semblable à Bénarès. L'histoire, racontée par lui-même, continue ainsi : «Cette idée aurait pu disparaître avec le temps, mais j'ai eu peu après l'occasion de voyager à l'étranger : il y avait beaucoup de cartes de ce style,

13. Le maharaja de Bénarès, dépourvu de pouvoir politique, demeure une personnalité clé de l'univers religieux local en tant que représentant de Shiva sur terre.

14. Les livrets adoptent systématiquement le calendrier luni-solaire vikram samvat commençant (à quelques ajustements près] en 5 ? avant notre ère et la conversion n'est pas toujours faite - la date figurant dans le livret est 1970.

15. En même temps que l'indépendance de l'Inde, acquise le 15 août 1947, I'Indian Independence Act voté par le Parlement britannique crée l'État indépendant du Pakistan, correspondant grossièrement aux régions de l'Empire colonial indien à majorité musulmane. 


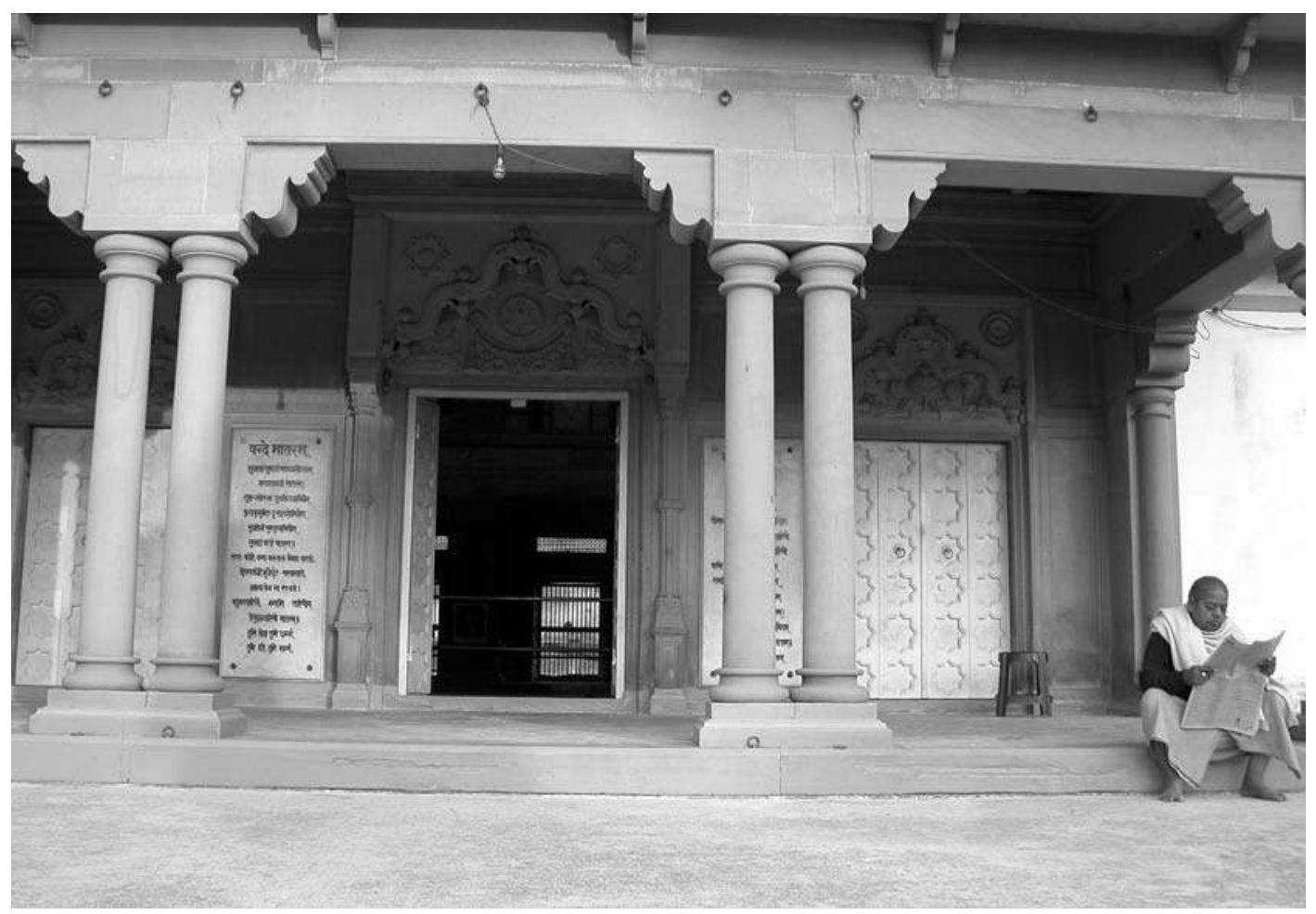

Fig. 5 Galerie d'entrée du temple, 2006. Photo M. C.

petites et grandes, au British Museum de Londres. Cela aussi n'était qu'une coïncidence, mais a affermi mon désir de construire une belle carte en relief. " On relève le détour par le British Museum, détour connu par tous ceux qui travaillent au temple et relevé dans les écrits relatant sa fondation. Double détour par l'Occident, en fait : celui de la cartographie au sens scientifique occidental, et celui du souci occidental de commémoration muséographique.

Les enjeux de la représentation cartographique de la nation indienne ont déjà été discutés (Assayag 2001; Bakker 1996; Brosius 2003; Ramaswamy 2003) : d'un côté la carte scientifique occidentale, son exactitude topographique, son absence de biais et même d'informations religieuses; de l'autre la carte hindoue, friande de représentations entremêlées des mondes divin et humain. Cette dernière tradition est très forte dans les lieux saints hindous, et particulièrement à Bénarès ${ }^{16}$. Au temple Bharat Mata, à l'inverse, c'est une représentation topographique « à l'occidentale " qui est exhibée. Issue de cette appropriation nationaliste de la cartographie occidentale, la carte reprend les frontières de l'empire des Indes, mais elle permet surtout aux Indiens de visualiser le territoire national unifié tel qu'il devait être défendu et dont ils allaient devenir les citoyens après l'indépendance.
Le récit se détourne ainsi des références à la divinité. Il n'est donc pas étonnant de constater que, contrairement à la plupart des autres temples, le rôle de la divinité dans la fondation de la carte et du bâtiment n'est ici mentionné nulle part : ni apparition en rêve, ni événement, ni signe. Mais la volonté du fondateur de relater rationnellement les événements qui l'ont mené à édifier le lieu ne s'affranchit pas toujours de l'idée d'une intervention divine : il parle de « coïncidences » et explique le retard de la construction par les "nombreuses difficultés et obstacles qui dépassent la maîtrise des hommes ". Cependant, malgré le fait que la déesse Bharat Mata incarne la puissance créatrice des dieux (shakti), ni le livret ni les discours locaux ne font référence au rôle que l'hindouisme attribue parfois à la divinité dans l'édification concrète des images et des temples, ou à l'idée ailleurs partagée d'une « descente »-incarnation de la divinité dans l'image que serait la carte. L'idée d'une création divine semble également conjurée par la « signature » de l'architecte et des porteurs de pierre, ainsi que par la photographie de l'architecte en chef, omniprésente dans les livrets comme dans l'enceinte du temple. La célébration de la mémoire des fondateurs

16. Comme l'a montré un récent projet pluridisciplinaire allemand (Gaenszle et Gengnagel 2006). 
et, plus généralement, des donateurs (qui ont financé la construction du temple) est pratique courante dans la plupart des lieux saints hindous. Mais, ici, le fondateur est au centre de l'attention : sa photographie, qui surplombe la carte, est décorée d'une guirlande renouvelée chaque matin, à l'instar des images de dieux (la déesse Bharat Mata) ou de personnalités particulièrement respectées (Gandhi). Le livret de présentation du temple énumère la liste des noms et résidences des cinquante-cinq individus qui ont construit le temple. Ils sont remerciés pour leur travail, sans aucune mention d'une inspiration autre que celle de «l'amour pour leur patrie ", et l'expression désormais consacrée par les nationalistes hindous, «dévotion à la patrie "-deshbhava-, est singulièrement absente. Devant ce quasi déni de la divinité à l'instant fondateur, il semble abusif d'assimiler le temple Bharat Mata à un lieu saint comme un autre.

\section{Une mythologie moderne et cosmopolite}

Le récit fondateur en appelle à l'amour de la patrie (qui est ici la « terre mère ») plus qu'à la dévotion, et préfère à l'intervention divine une chronologie « factuelle » et "objective ». Le fondateur nous apprend ainsi comment il s'est aidé des conseils de spécialistes et d'érudits avant d'opter pour le marbre, justifiant un choix raisonné à l'opposé d'une inspiration divine. Suit une description des caractéristiques physiques de la carte (taille, échelle) qui insiste sur l'exactitude de la reproduction : «Tous les efforts ont été réunis pour montrer chaque lacet de rivière et leurs [sic] parcours précis. Rien n'a été laissé au hasard: non seulement les trajets, mais aussi la profondeur et la largeur des principales rivières sont fidèlement reproduites, pour le plus grand bénéfice du visiteur. » En bon scientifique, Shiv Prasad Gupta cite même ses sources, à savoir les nombreuses publications du Survey of India Department, qu'il remercie.

La modernité dont se revendique systématiquement le temple est ambiguë : selon les contextes, elle renvoie tantôt à l'Inde moderne (séculariste et industrielle) rêvée par Nehru, tantôt à la modernité aux accents fascisants des fondamentalistes (suprématie de la nation et de l'homme hindous) [Van der Veer 1994]. Quoi qu'il en soit, pareil temple "moderne » se doit de faire preuve d'un souci d'universalisme. Au premier étage, depuis cette galerie circulaire d'où il surplombe la carte, le visiteur est invité à admirer les murs ornés de plaques où

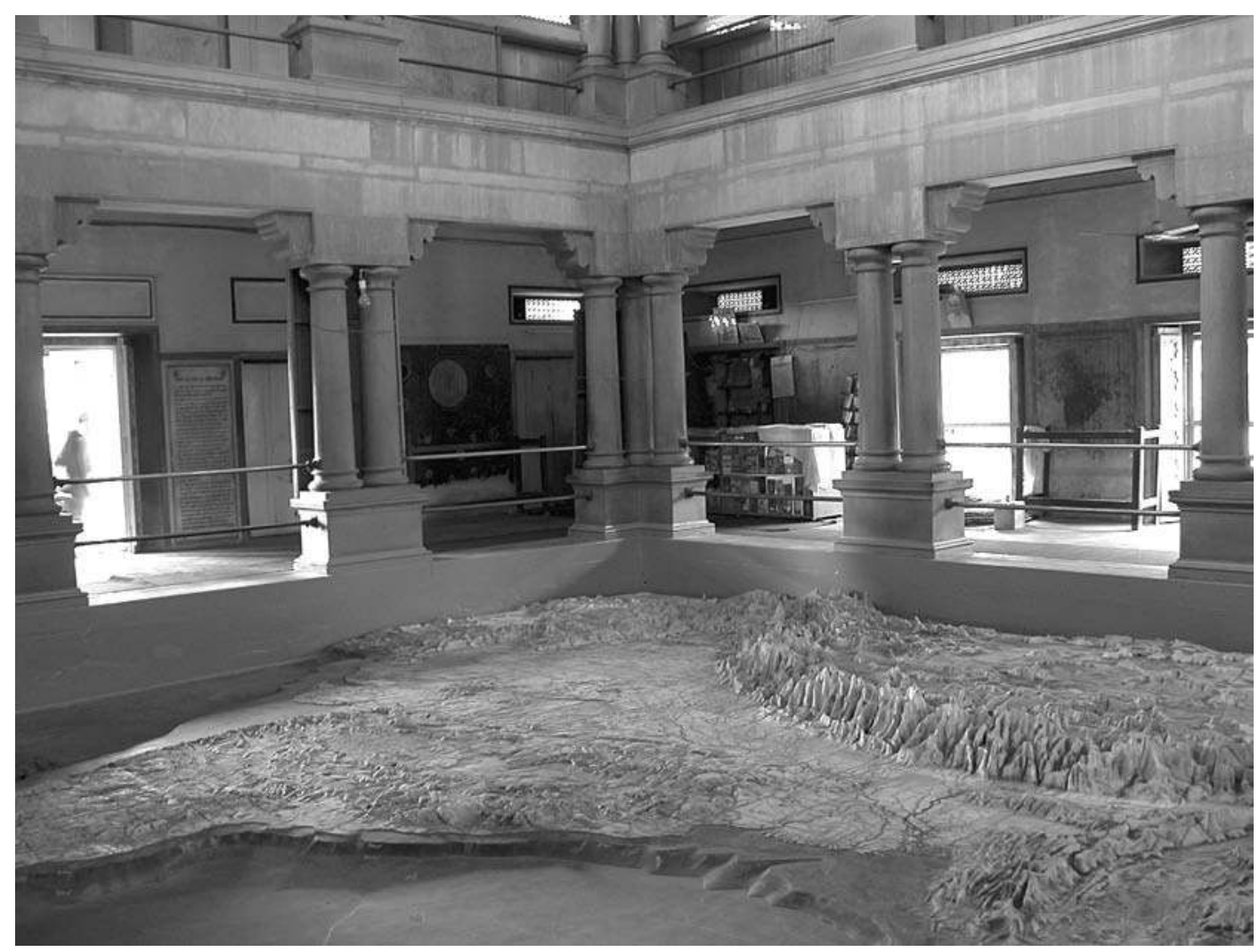

Fig. 6 Vue de l'intérieur du temple, carte en relief, 2006. Photo M. C. 


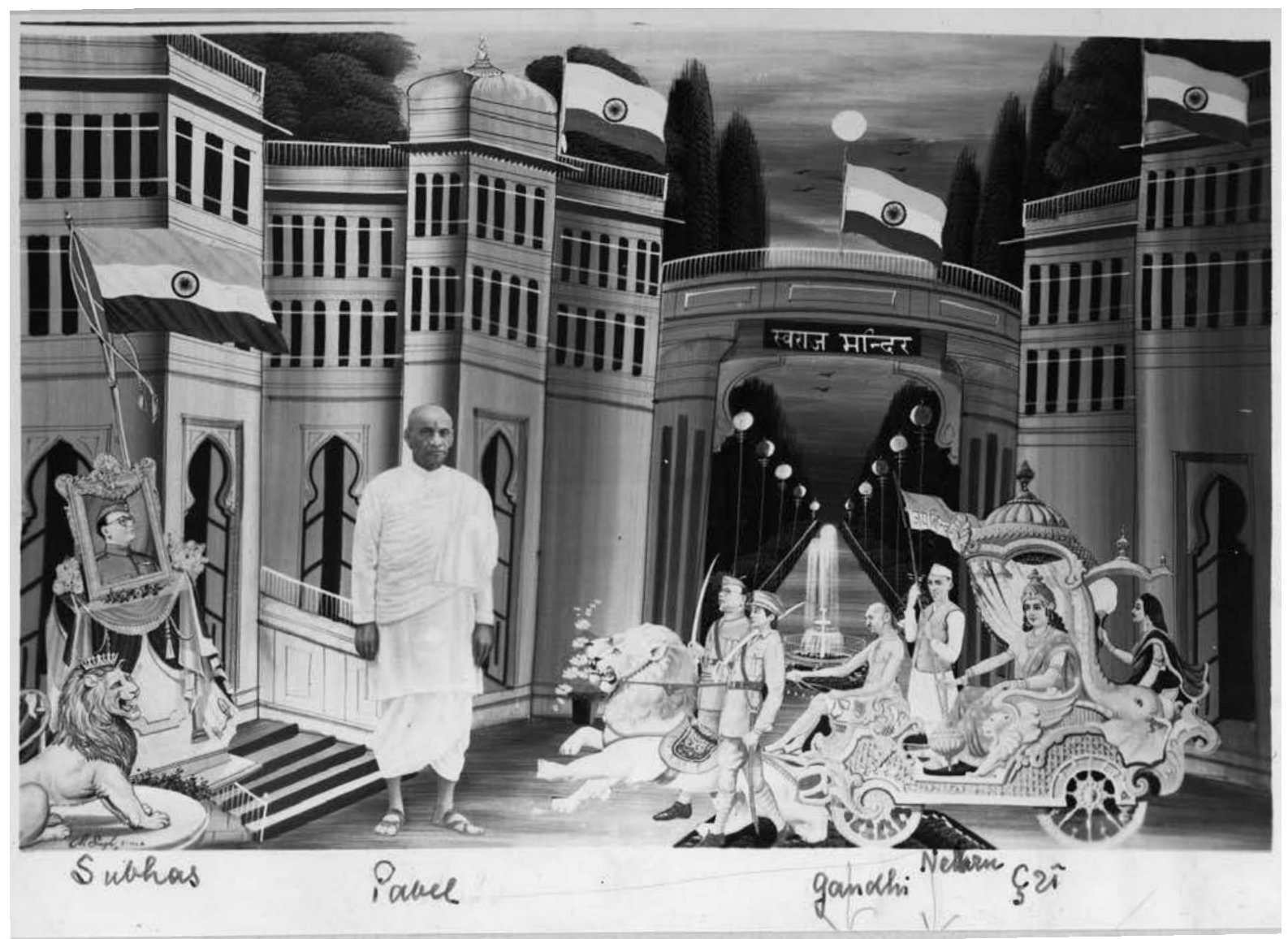

Fig. 7 Iconographie populaire représentant les héros de l'Indépendance, dont Gandhi et Nehru sur le char, conduisant la déesse Mère Inde au «temple de la nation " (inscription au fronton sous le drapeau indien). ( ) EFEO.

sont gravés « tous » les alphabets du monde (de l'écriture sémitique aux différentes langues indiennes), ainsi que les systèmes numériques. Comme lors d'une visite de musée, les visiteurs sont conviés à l'exposition de productions scientifiques insistant sur l'inscription de l'Inde et du temple dans l'histoire universelle. Au-delà même de cette histoire des civilisations, l'Inde se positionne au sein d'une topographie cosmique : quoique partiellement effacées, les représentations des systèmes planétaires qui entourent la carte sont également proposées à l'édification du pèlerin par les guides, qui vantent leur exactitude et la somme de travail qu'elles ont demandée.

Pareil universalisme sous-entend parallèlement un œcuménisme local, c'est-à-dire une ouverture à l'ensemble des castes et religions indiennes ${ }^{17}$. L'héritier du fondateur explique: This is a temple for consciousness of identity in the mirror of nation building. It is necessary to have a temple to take conscious [sic] of unity of territory because there are diverse religious cultures in
India. Hariram Singh aime ainsi souligner que des musulmans figurent parmi ces combattants de l'Indépendance indienne auxquels le temple est dédié, et que le critère de reconnaissance n'est donc pas ici la religion, mais le rôle joué dans la construction d'une identité nationale unifiée. En ce sens, Abdu Kalam Azad, indépendantiste musulman, a sa place au Bharat Mata, contrairement à Jinnah qui, défenseur d'une patrie séparée pour les musulmans, représente la lutte opposée, celle du démembrement de Mère Inde.

Ainsi que Hariram Singh le résume : “C'est un temple moderne. Avant, les temples étaient pour les brahmanes, les kshatriya ou les shudra [les différentes castes].

17. Le souci d'universalisme s'exprime aussi à travers la personnification de l'Inde dans une divinité féminine comme symbole de l'importance du rôle de la femme dans la culture hindoue, argument régulièrement avancé à Bénarès, mais aussi au temple de Mère Inde de Haridvar, pour commenter l'étage complet consacré aux héroïnes de l'histoire indienne, contre-pied explicite de « ceux qui pensent que les femmes sont exploitées dans notre culture » (dixit le site Internet officiel du temple). 
Ici, il n'y a qu'une carte de l'Inde. Mère Inde. Tout le monde est pareil. Les petits et les gros. Toutes les castes viennent. Même les musulmans. Tous les fils de Mère Inde sont pareils. C'est pour ça que c'est un temple moderne. » Et puis, plus synthétique encore : Here, no religious [sic]. All religions. Il est vrai que le temple fut inauguré sous les auspices gandhiennes du combat pour une Inde indivise, c'est-à-dire non séparée du Pakistan, où cohabiteraient hindous et musulmans. C'est ce vœu qu'exprima Gandhi lors de son discours inaugural vibrant de la même glose œcuménique : « Dans ce temple, il n'y a pas de statues de dieux ou de déesses. J'espère que ce temple jouera le rôle d'une plateforme universelle pour toutes les religions, ainsi que pour les harijan [intouchables] et pour toutes les castes et croyances, et qu'il contribuera aux sentiments de l'unité religieuse, de la paix et de l'amour dans ce pays " (cité in Gupta 2001 : 4292).

Cependant, l'œcuménisme (notamment gandhien) ne niant pas la pertinence des hiérarchies, l'idéologie hindoue du système des castes reste prégnante. Ainsi, dès l'inauguration du temple, on aurait distribué aux intouchables du savon pour qu'ils aillent se « laver » avant de participer au repas intercommunautaire (ibid.)... L'idéologie de la pureté sous-jacente au système des castes ne saurait se satisfaire d'une toilette au savon comme mode de neutralisation du danger de la souillure que représente l'intouchable. Faut-il voir là une variante moderne et sécularisée du rapport à l'impur? Quoi qu'il en soit, l'anecdote est révélatrice de la situation inconfortable des élites indiennes occidentalisées vis-à-vis du système des castes et de ses fondements religieux; elle illustre clairement le compromis entre deux idéologies, deux visions du monde, caractéristique de la démarche qui mena ces élites à fonder le temple dédié à Mère Inde.

En lieu et place d'un mythe fondateur classique, le récit $d u$ fondateur commémore et mythifie la construction historique d'un territoire à travers, d'une part, la mémoire de la lutte politique et, d'autre part, l'exhibition de la dimension rationnelle et séculière d'une Inde moderne et unifiée incarnée par la carte en relief. L'héritier du fondateur précise : « La carte est une indication de la nation [indienne], pas du rashtra [la nation hindoue]. En venant dans un temple, les gens cherchent une statue. Ici, il y a autre chose. " Et c'est cette autre chose, avec sa charge de science rationnelle mais aussi de relecture de l'histoire, qui à la fois conjure le contexte religieux du temple et cristallise sa mythologie de «temple moderne ».

\section{La lecture hindouiste}

Faire œuvre de mémoire en en appelant autant à l'amour de la patrie qu'à l'objectivité scientifique : il fallait bien un lieu à la fois temple et musée pour concilier pareils objectifs. Mais l'interprétation de l'histoire n'est jamais figée, moins encore dans l'Inde contemporaine qui voit les nationalistes hindous disputer aux tenants de l'Inde séculariste le monopole de la construction de l'identité indienn $\mathrm{e}^{18}$. Pour les hindouistes, régulièrement au pouvoir depuis 1998, Mère Inde est devenue la clé d'une rhétorique comparant la partition à un démembrement de la déesse et considérant les lieux de culte musulmans comme autant de violations (voire de viols tout court) de son intégrité. Rien d'étonnant dans ce contexte à ce que la lecture actuelle des temples de Mère Inde les fasse évoluer de lieux de construction de l'indianité à des lieux d'affirmation de l'hindouité. Alors, si le Bharat Mata, en tant que temple, est virtuellement un territoire divin (kshetra) sur lequel régnerait une divinité (la déesse Bharat Mata), il illustre surtout, par la substitution de la carte de l'Inde à l'image divine, une tentative d'assimilation du territoire indien à la divinité.

Or, à visiter le Bharat Mata, il est clair que la définition de ce territoire n'est pas bien stable. Ainsi, les frontières du territoire représentées sur la carte centrale du temple sont celles de l'Akhand Bharat, l'Inde indivise comprenant le Pakistan et le Bangladesh. L’héritier du fondateur justifie ces frontières en soulignant que la date de fondation, 1936, est bien antérieure à l'indépendance et à la partition entre Inde et Pakistan. Ce faisant, il « oublie " que les frontières dessinées dépassent même celles de l'ancien Empire britannique. Il est vrai que la cartographie a été réactualisée : les tickets de donation, le panneau de présentation du temple planté dans le jardin et le panneau d'entrée sont bien postérieurs à l'indépendance, et respectent le découpage historique d'après la partition (sauf pour le Sri Lanka, étrangement présent). Ainsi, l'objectivité figée dans le marbre que devait représenter la carte du territoire indien est dépassée par l'évolution historique à laquelle s'adaptent mieux les supports temporaires, renouvelables et adaptables que sont les tickets ou panneaux.

18. L'ex-Premier ministre indien Lal Krishna Advani a défendu l'importance selon lui méconnue de Sardar Patel dans les luttes indépendantistes. Patel était le moins séculariste des congressistes. Advani dit regretter le rôle que l'histoire a donné à Nehru et à sa descendance, et que « l'on croie que la défense de l'Inde n'a été l'affaire que d'une seule famille » (The Times of India, 29 octobre 2003). Patel était, avec Gandhi, au temple Bharat Mata de Bénarès le jour de l'inauguration. 
Cependant, ces tentatives de réactualisation de l'objectivité cèdent aujourd'hui le pas à l'idéologie politique de l'hindutva (" hindouité) des nationalistes hindous pour qui, ainsi que l'exprime leur représentant Savarkar, « la seule limite géographique de l'hindouité est la limite de notre terre » $(1964: 74)$. Sans doute cette « déterritorialisation de l'hindouité » est-elle également à mettre en relation avec l'importance de la déesse Bharat Mata dans les milieux de la diaspora indienne (Assayag 2001 : 206) qui constitue l'essentiel des mécènes (et une partie des visiteurs) du temple de Bénarès, d'après l'héritier du fondateur qui explique que "l'amour pour Mère Inde est souvent plus fort chez ceux qui ne vivent pas en Inde, justement parce qu'ils en sont éloignés ».

L'ambiguïté fondatrice (un lieu commémoratif de l'histoire et de l'unité indienne bâti sur le modèle d'un temple) est habilement utilisée par les nationalistes hindous. Ainsi, le texte Vande mataram, présence leitmotiv sur les murs du temple, est déjà fortement ambigu : il ne fut accepté en 1937 comme « chant national » (national song ${ }^{19}$ ) par le parti du Congrès qu'après d'âpres controverses du fait de l'esprit anti-musulman du texte dont il est extrait (ibid. : 202). La controverse a repris de l'ampleur depuis que les nationalistes hindous sont au pouvoir, la question étant notamment de décider si le texte doit être chanté dans les écoles alors que certains musulmans et sikhs s'y refusent (Pagani 2007: 135). Le choix d'inscrire ce chant sur les murs du temple, à la fois patriotique et religieux (Bhattacharya 2003), participe naturellement de l'ambivalence du lieu, entre culte et nationalisme.

Mais les nationalistes hindous ne se contentent pas de l'ambiguité fondatrice ; leur stratégie vise clairement à faire pencher l'équilibre interprétatif du côté d'un lieu dédié à la nation hindoue divinisée. Ainsi, à l'occasion de la fête d'Indépendance commémorée au temple de Bénarès en 2005, les responsables ont accédé à la demande des nationalistes hindous du RSS ${ }^{20}$ d'installer à l'entrée de la pièce principale un poster géant de la carte de l'Inde. Or ce poster réintroduit à travers la représentation originelle de la carte (celle de l'empire des Indes, grossièrement) les frontières d'une Inde fantasmée par les nationalistes. Surtout, la « Grande Inde » est recouverte d'une représentation de la déesse Bharat Mata, ce qui laisse beaucoup moins de place à une quelconque interprétation pluriconfessionnelle du lieu. Hariram Singh souligne d'ailleurs avec regret : "Maintenant, les musulmans ne viendront plus parce qu'ils ne peuvent pas vénérer une image. Avant, il n'y avait pas d'image. » D'autant plus que l'iconographie est loin d'être neutre : si la déesse n'a que deux bras et ne porte pas le trident, la présence du tigre, monture de Durga, suffit à signifier l'assimilation de la Bharat Mata récente à la classique Durga. D'autres symboles, tels la flamme émanant de sa tête, le sari rouge et le drapeau rouge hindou (en lieu et place du drapeau national indien généralement représenté dans l'iconographie de Bharat Mata), renvoient directement à l'image de la déesse mère spécifiquement répandue dans les cercles nationalistes hindous (Ramaswamy $2006: 183)$.

\section{L'échec de Bénarès; le succès de Haridvar}

Afin de ne pas présumer de la réceptivité des acteurs locaux à la manipulation politique du religieux pilotée par les nationalistes hindous, il convient de l'évaluer à partir d'un cas d'ethnographie.

La carte de l'Inde se veut une production totale, dont on vante aussi bien les qualités artistiques, techniques et scientifiques que les vertus esthétiques et émotionnelles. Reste à déterminer l'interprétation qu'on en fait, et l'écho qu'elle reçoit chez les visiteurs. Pour ce guide d'un car de pèlerins de Lucknow, la visite du temple fait partie du " package » du pèlerinage : «De plus en plus de groupes me demandent cette visite. " Mais il ajoute aussitôt que, pour ces pèlerins qui arrivent en car des districts ou États frontaliers et qui font une visite guidée d'un quart d'heure, « on ne vient [au temple de Bharat Mata] que quand on a fini le pèlerinage ». D'autres visiteurs se considèrent explicitement comme des « touristes " visitant un «musée » : ce sont pour l'essentiel des couples aisés en voiture individuelle ou avec chauffeur, qui viennent des villes nord-indiennes, parfois accompagnés de guides municipaux qui leur proposent exactement la même visite qu'aux pèlerins.

Cela renvoie au rôle du pèlerinage dans le développement récent du tourisme de masse en Inde. Mais ici, au-delà du fait que la religiosité hindoue n'est pas exclusive de préoccupations mondaines, récréatives ou touristiques, la scientificité de la carte, sans rebuter le pèlerin moderne, suscite beaucoup plus la curiosité que

19. L'hymne national (national anthem) de l'Inde à proprement parler est un autre texte (Jana Gana Man), à l'esprit plus séculariste, composé par Rabindranath Tagore.

20. Association politique aux activités paramilitaires, le RSS - Rashtriya Svayamsevak Sangh, «Association des volontaires nationaux » - veille, sous couvert notamment d'action sociale, à restaurer un hindouisme qu'elle estime affaibli. 


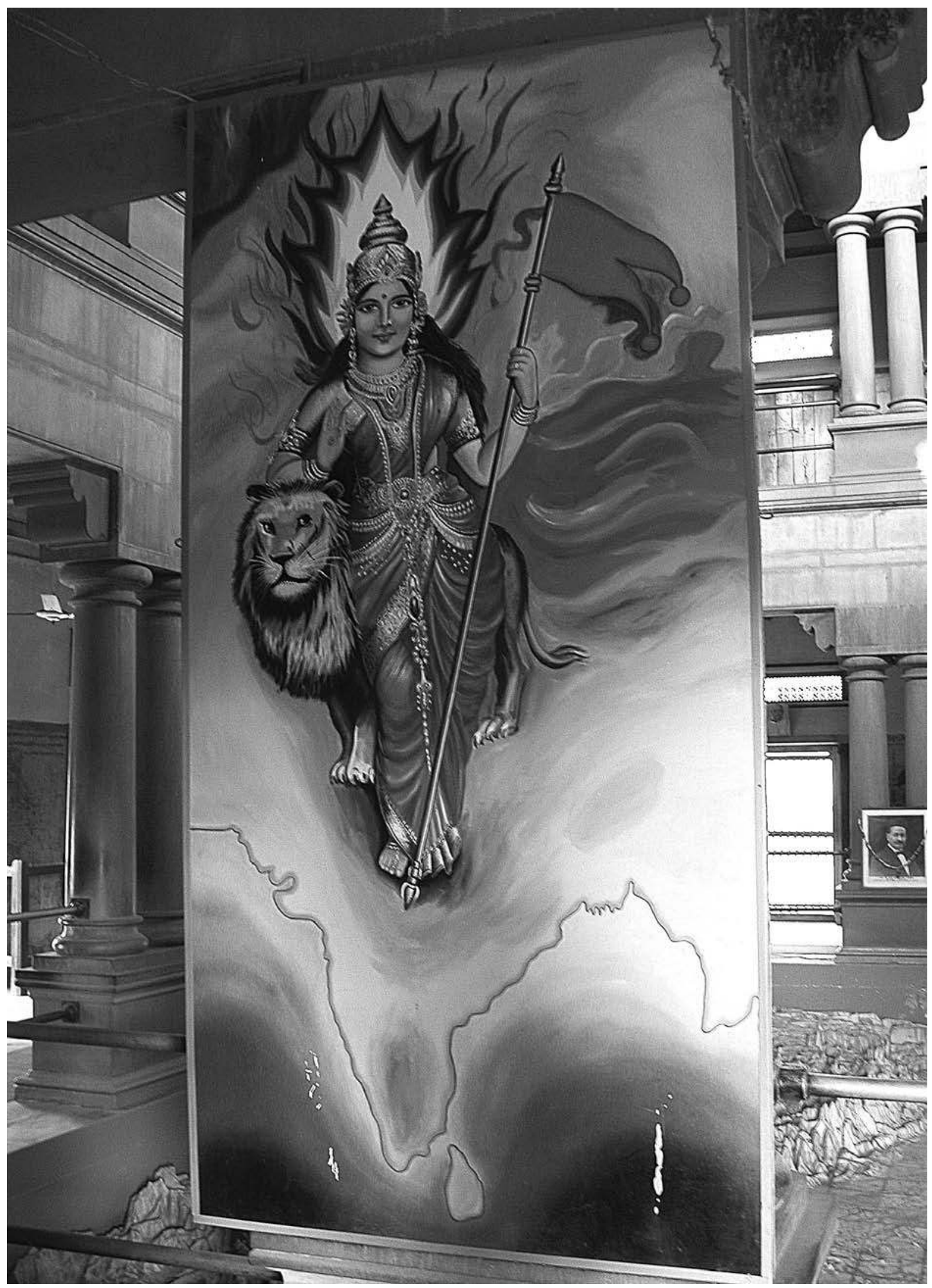

Fig. 8 Devant la carte en relief : le poster frappé de la déesse Bharat Mata, 2006. Photo M. C. 


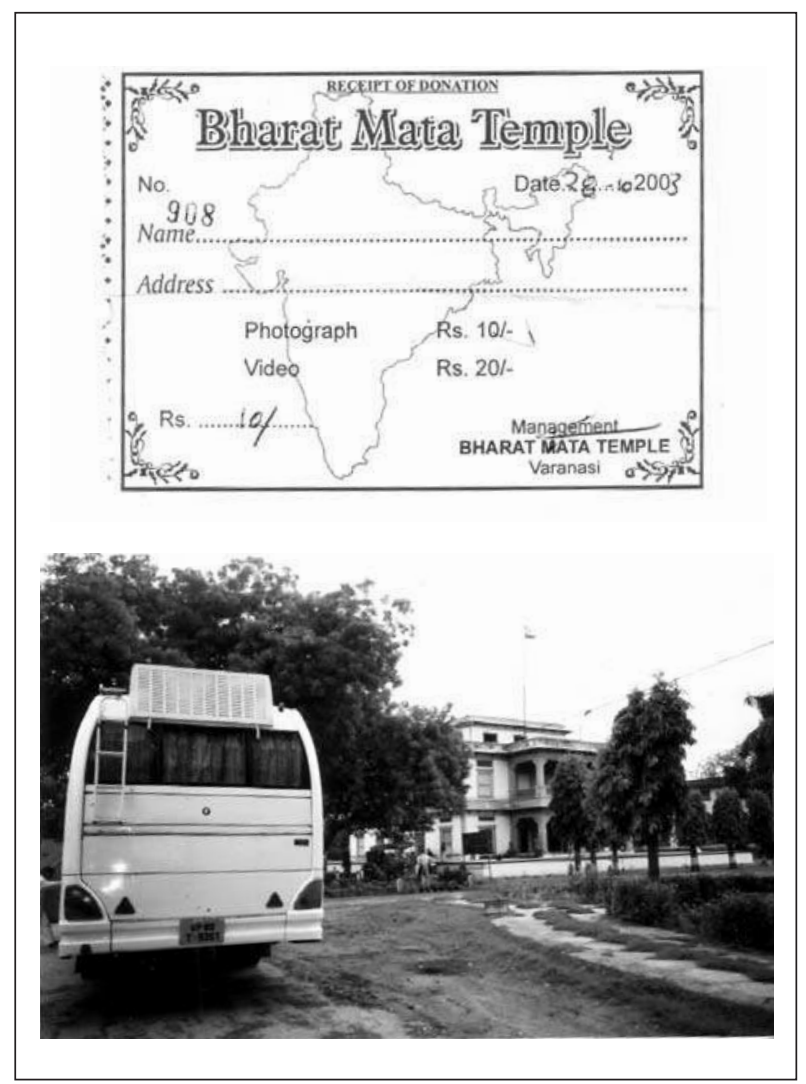

Fig. 9 Ticket de donation avec carte - bus de pèlerins, 2003. Photo M.C.

la dévotion. Concrètement, le tour de la carte, lors des visites guidées, se fait très souvent dans le sens inverse des aiguilles d'une montre, dans le sens inverse, donc, de la déambulation rituelle hindoue (pradakshina parikrama), qui exige de garder la main droite, pure, du côté du divin. Ce qui ne laisse pas d'étonner dans le cas de pèlerins venus à Bénarès pour circumambuler lieux saints et territoire sacré, et jamais en sens inverse. Plus généralement, aucun geste de dévotion, et encore moins aucune émotion dévotionnelle, n'accompagne la visite du temple. Il est tentant de penser la visite comme la circumambulation d'une représentation cartographique centrale figée dans une éternité sacralisante mais rythmée, contextualisée et animée par, tout autour, la galerie de portraits des héros combattants au service de la nation que la carte figure. Cependant, comme le remarque le guide des pèlerins, « les couleurs [des portraits] sont passées, et il n'y a pas d'explications racontant les exploits des uns et des autres. Les gens ne les connaissent pas tous! Du coup, ils sont moins intéressés ». Pourtant, si la plaidoirie pour une muséographie plus explicite rejoint les attentes de certains visiteurs, ceux d'entre eux que j'ai interrogés savaient identifier la grande majorité des portraits. Il semble en fait que la dimension pédagogique, scientifique et rationalisante de la "mise en scène " évoquée plus haut ne stimule tout simplement pas l'implication du visiteur dans sa relation à cette Mère Inde, divinité ou territoire. L'ambition pédagogique nationaliste censée induire une prise de conscience de l'unité indienne ne semble pas non plus adaptée au public effectif du temple banarsi. La plupart des visiteurs à qui j'ai demandé de dessiner de mémoire une carte de l'Inde (avant leur entrée dans le temple) se sont plutôt bien acquittés de leur tâche, représentant au moins un triangle et situant grossièrement les pôles urbains et l'Himalaya. Ils avaient tous été scolarisés, possédaient au moins des rudiments d'anglais et n'avaient nul besoin de la carte pour se représenter le territoire indien.

La difficulté de ce temple à trouver un public sensible à sa pédagogie apparaît également de manière concrète : les seuls dons qu'il reçoive sont les dix et vingt roupies payées par les visiteurs pour pouvoir prendre des photographies ou filmer (le ticket indique : "reçu de donation »). Ainsi que l'explique Hariram Singh, intéressé par cet aspect des choses puisqu'il tire une grande partie de ses revenus des dons des visiteurs : " Personne ne vient au temple, parce qu'il est trop loin du Gange et du Shiva Mandir [principal temple de Bénarès, au centre de la vieille ville]. Il faut que les gens restent une nuit, alors le lendemain matin, ils ont le temps de passer au temple [Bharat Mata], et même là, ils sont peu nombreux parce qu'il faut toujours payer : pour le parking des bus, pour les chaussures, pour prendre des photos, etc. " De fait, c'est le problème global du temple banarsi : rester, comme la boîte d'offrande, le plus souvent vide.

L'analyse gagne ici à mettre ce temple en perspective avec un autre temple Bharat Mata, construit à Haridvar près d'un demi-siècle après celui de Bénarès. Les fondateurs de ce second temple, bien que prétendant s'inspirer du premier, ont choisi une perspective bien différente qui en fait aujourd'hui le plus célèbre des deux ${ }^{21}$. Construction moderne de huit étages en marbre blanc, il fut fondé en 1983 par une figure hindouiste : Swami Satyamitranand Giri («saint homme ", membre de l'organisation religieuse nationaliste Vishva Hindu Parishad). En guise d'image divine, il propose également au pèlerin une carte de l'Inde. Le temple,

21. Mon développement sur le temple de Haridvar est fondé sur sa description in McKean (1998) ainsi que sur le commentaire qu'en font de nombreux sites Internet indiens. 
comme à Bénarès, n'échappe pas à la comparaison récurrente avec un musée : la plupart des images divines sont présentées sous vitrine et identifiées par des étiquettes, et des programmes multimédia exposent la culture indienne. Un site Internet indien présente explicitement le temple comme dédié à la nation indienne : «Ses huit étages sont décorés de scènes et d'images d'événements et de personnages associés au pays [country]" (www.blessingsonthenet.com). Mais l'orientation est cette fois nettement plus religieuse. Il y a à Haridvar un véritable mythe fondateur, avec comme point de départ une vision divine accordée au saint homme. Autant le temple banarsi illustre bien les stratégies des années 1930, lorsque le sécularisme était un rempart contre le communalisme (Jaffrelot 1993 : 109 et suiv.), autant celui de Haridvar souligne "l'érosion [dans les années 1980] du sécularisme comme problématique légitime » (ibid.). Avant même d'avoir accès à la carte de l'Inde, le visiteur pénètre dans un sanctuaire dédié à une statue de la déesse hindoue Bharat Mata, dont il prend la « vision » (darshan), et qui fut consacrée par un rite réalisé par Indira Gandhi² ${ }^{22}$ Plusieurs divinités hindoues (Shiva, Vishnu, Sati) sont également présentées au visiteur. Parmi les héros des nationalistes à Haridvar, on remarque la présence de Shivaji ${ }^{23}$, dont le temple banarsi ne fait nulle part mention, et l'absence de Nehru, le symbole de l'Inde séculariste. Autre symbole parlant : le temple de Haridvar est coiffé d'un drapeau rouge comme tous les sanctuaires hindous dédiés à des divinités classiques, alors que celui de Bénarès est orné du drapeau indien tricolore (frappé du symbole bouddhiste de la roue du Dharma!).

À un autre niveau, le temple de Haridvar est quotidiennement animé par un ashram où résident pèlerins, touristes et leaders religieux, ainsi que par des activités rituelles régulières organisées par le fondateur. En outre, ses huit étages, qui ont coûté plus de dix millions de roupies (environ deux cent cinquante mille euros), ont été inaugurés devant plus de cent mille personnes avec sacrifice védique et représentations de la Rama lila (geste du dieu Ram en tant que symbole du roi hindou). À Bénarès, en revanche, les seules commémorations sont celles du Freedom Fighters Day (26 janvier) et de la fête d'Indépendance (15 août), deux fêtes « historiques » au cours desquelles un petit groupe de politiciens locaux, ainsi que les autorités policières et militaires banarsi, se réunissent pour le lever du drapeau indien. Remarquons qu'il s'agit de festivités réunissant les autorités plus que les fidèles, les pèlerins ou les acteurs individuels locaux, décidément peu concernés.
À Bénarès, une carte mise en musée résiste aux tentations d'une interprétation religieuse, sans trouver son public et sans que l'enjeu politique potentiel d'une sanctuarisation du territoire national soit mobilisé. Le temple est gardé par un individu sans arme alors que de nombreux sanctuaires banarsi, y compris celui dédié au dieu singe Hanuman à cent mètres du Bharat Mata, sont surveillés par deux policiers bien armés par peur des attentats ou des émeutes. Comme si le temple d'une Inde unifiée et séculariste ne représentait pas, ou plus, un lieu symbolique de la ville sainte de Bénarès et des relations intercommunautaires. Faut-il conclure sur l'échec de cette tentative muséographique prétendant, sans renoncer au modèle apparent du temple, rompre avec le rite et la dévotion et lui substituer un patriotisme séculier bien moins évocateur pour le pèlerin contemporain ? Le contre-exemple de Haridvar pourrait le laisser penser : les nationalistes hindous ont, là, récupéré la carte séculariste mise en musée, eux dont la stratégie consiste justement à mettre en temple le plus possible leur idée de nation, leur action politique et jusqu'à leurs leaders. Ils ont su tirer profit de l'association cartetemple-musée pour en faire, d'une part, un lieu populaire de construction et de manipulation des idées de territoire et d'identité et, d'autre part, d'exposition « éducative » (ou de propagande) de ces idées.

La valorisation du territoire indien, plus ou moins sacralisé, n'est pas une invention des nationalistes d'aujourd'hui : elle était utilisée dès la lutte indépendantiste, y compris par le séculariste Nehru, et le glissement n'a fait que s'accentuer depuis. Les temples dédiés au territoire indien illustrent ces stratégies et leur évolution.

Parallèlement au contexte historique, c'est ici l'analyse ethnographique des discours des promoteurs (rendant intelligibles leurs intentions et leur idéologie) ainsi que des pratiques locales qui a permis de rendre compte de la construction dynamique d'un espace qui, pour être très investi idéologiquement, n'en est pas moins l'objet d'interprétations variées et évolutives.

À Bénarès, le temple fut fondé par un militant indépendantiste lié à l'idéologie gandhienne. Les responsables actuels ont hérité des ambiguités de cette idéologie; ils évoluent également avec la nouvelle donne du nationalisme hindou contemporain. L'enjeu est aujourd'hui

22. Indira Gandhi avait mis certaines organisations nationalistes hindoues hors la loi et fait inscrire le sécularisme dans la Constitution en 1975 , mais elle avait, ensuite, multiplié les appels du pied aux nationalistes hindous (Jaffrelot $1993: 320$ ).

23. Roi hindou du Maharashtra ( $\mathrm{xv \|}{ }^{\mathrm{e}}$ siècle), figure de proue des nationalistes. 
de savoir si le temple restera ce musée abritant une carte curiosité témoin d'une volonté politique d'hier ou s'il sera récupéré par la rhétorique hindouiste. Les tenants d'une Inde séculariste (ils s'appellent secular forces) en ont conscience et ils tentent, à leur tour, d'influer sur la lecture du temple : ils ont justement choisi le temple Bharat Mata de Bénarès pour tenir (le 26 juin 2003) un meeting de sensibilisation au danger du nationalisme hindou pour l'Inde séculière.

À Haridvar, le temple illustre et entretient la rhétorique de l'indianité, version propagande hindouiste. En partie parce que la religiosité hindoue est inséparable de l'attachement à l'espace (ce que Eck [1981:323] appelle the locative strand of Hindu piety), le territoire sacré hindou est souvent présenté comme consubstantiel à la géographie nationale. Les nationalistes trouvent là le support idéal de leur revendication d'une superposition quasi parfaite entre Inde et hindouisme, remettant ainsi en cause le sécularisme indien au profit de la promotion de l'hindutva. Ce faisant, d'un musée à la gloire de la nation séculière indienne construit sur le modèle d'un temple, on passe à un temple à la gloire de la nation hindoue sacralisée construit sur le modèle d'un musée.

Mais quelle que soit la lecture (fondamentaliste ou séculière) que chacun fait de ces temples musées dédiés à Mère Inde, la carte installée comme substitut d'une image divine cristallise un enjeu identitaire fort. La mettre en temple suppose un recours à la fois à la fonction légitimante de la religion et à sa capacité pédagogique ou édifiante. Dans cette perspective, la dimension muséographique didactique sert, elle aussi, dans les deux temples, les rhétoriques nationalistes. Ces rhétoriques reposent, à Haridvar, sur l'histoire indienne mêlée de mythologie hindoue. À Bénarès, même si les fondateurs et leurs héritiers s'attachèrent à promouvoir une vision séculière de la nation, leur rhétorique n'en repose pas moins sur la transformation de l'histoire indienne en une mythologie. Dans les deux cas, l'amalgame entre la référence religieuse, la convocation de l'histoire et l'appropriation des concepts occidentaux de nation et de modernité font qu'au-delà de leurs différences, ces temples à Mère Inde illustrent deux facettes d'un même projet politique et idéologique : la construction d'un mythe de la nation indienne.

mots clés / keywords : musée // museum • temple // temple - Inde // India • nationalisme // nationalism • territoire // territory.

Centre d'études de l'Inde et de l'Asie du sud mathieu.claveyrolas@laposte.net

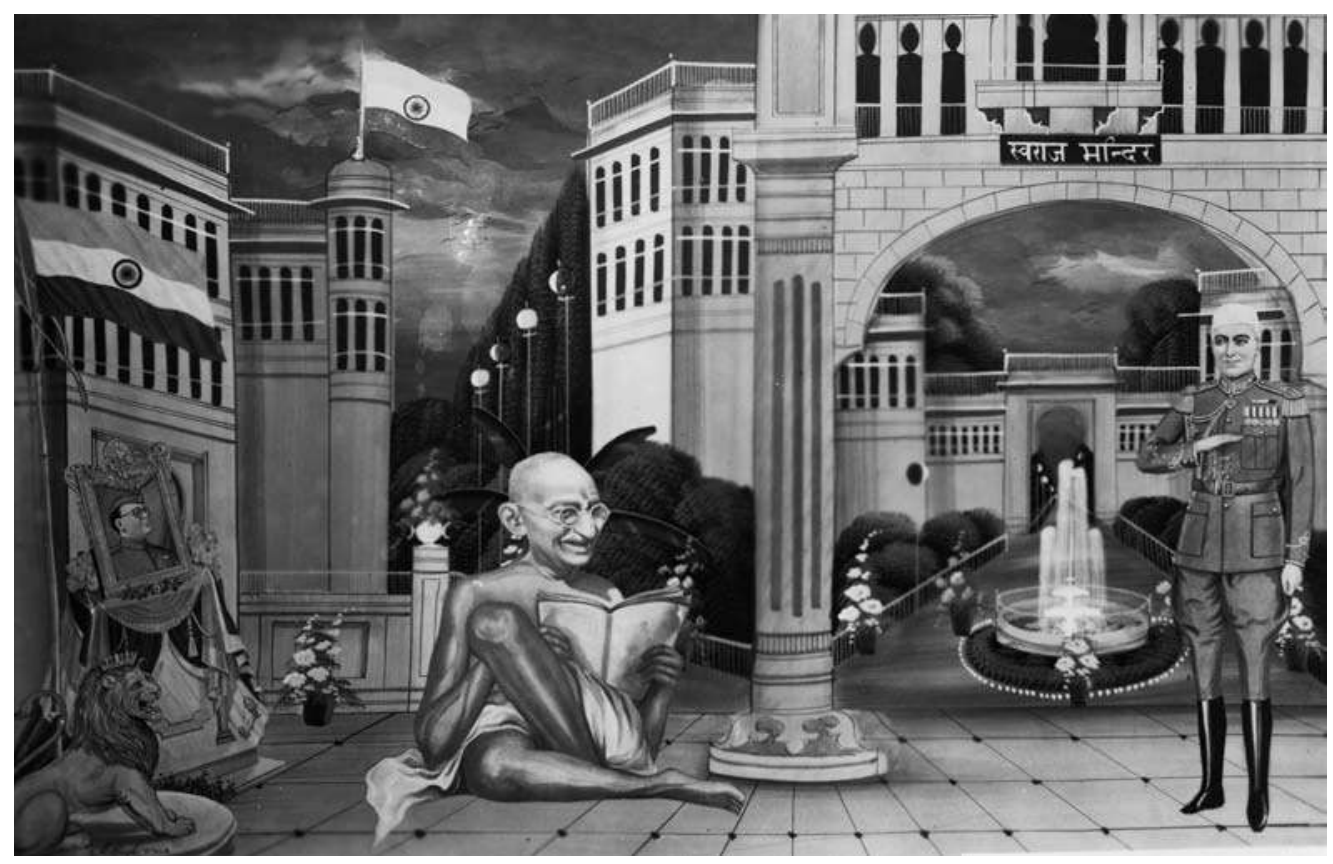

Fig. 10 Iconographie populaire représentant les héros de l'indépendance devant « le temple de la nation » (inscription au fronton du bâtiment). @ EFEO. 


\section{Bibliographie}

\section{AssAYAG, Jackie}

2001 L'Inde. Désir de nation. Paris, Odile Jacob.

\section{BAKKER, Hans}

1996 « Construction and reconstruction of sacred space in Varanasi », Numen 43.

\section{BHARDWAJ, Surinder $M$.}

1973 Hindu Places of Pilgrimage in India. Berkeley, University of California Press.

1999 « Circulation and circumambulation in tirtha yatra », conférence Pilgrimage and Complexity. New Delhi, Indira Gandhi National Centre for the Arts, 5-9 janvier

(version électronique : www.colorado.edu/Conferences/pilgrimage).

\section{BHATTACHARYA, Sabyasachi}

2003 Vande Mataram, the Biography of a Song. New Delhi : Penguin.

\section{Brosius, Christiane}

2003 «Mappare il corpo della nazione. Le processioni territoriali nei video di propaganda della destra indù », Etnosistemi 10, Daniela Berti et Gilles Tarabout (éd.) : 130-144.

2005 Empowering Vision: The Politics of Representations in Hindu Nationalism. Londres, Anthem Press.

\section{Claveyrolas, Mathieu}

2003 Quand le temple prend vie. Atmosphère et dévotion à Bénarès. Paris, CNRS.

2006 «Le musée d'un lieu saint en chantier. L'église de la Sagrada Família entre archives et achèvement virtuel », Gradhiva 6 , nouvelle série.

\section{EcK, Diana}

1981 «India's tirthas: crossings in sacred geography », History of religions 20[4].
1985 «Banaras: cosmos and paradise in the Hindu imagination », Contributions to Indian Sociology 19[1].

1998 « The imagined landscape: Patterns in the construction of Hindu sacred geography », Contributions to Indian Sociology 32(2).

Gaenszle, Martin et Gengnagel, Jörg 2006 Vizualizing Space in Banaras. Images, Maps and the Practice of Representations. Wiesbaden, Harrassowitz.

Galinier, Jacques et Molinié, Antoinette

1998 «Le crépuscule des lieux. Mort et renaissance du musée d'Anthropologie », Gradhiva 24 : 93-102.

\section{GuPTA, Charu}

2001 « The Icon of Mother in Late Colonial North India », Economic and Political Weekly 36(45).

\section{JAFFrelot, Christophe}

1993 Les Nationalistes hindous. Paris, Fondation nationale des sciences politiques.

\section{McKeAn, Lise}

1998 « Mother India and Her Militant Matriots 》, in John Stratton Hawley et Donna Marie Wulff (éd.), Devi. Goddesses of India. Delhi, Motilal Banarsidass : 250-280.

\section{PAGANI, Frédérique}

2007 «Servir les hommes, c'est servir le Seigneur. » Le salut par la philanthropie. Étude d'une association de bienfaisance sindhie, thèse de doctorat. Université Paris X-Nanterre, non publiée.

\section{PinNey, Christopher}

2004 Photos of the Gods. The Printed Image and Political Struggle in India. Londres, Reaktion Books.

\section{RAMASWAMY, Sumathi}

2003 « Visualizing India's Geo-Body: Globes, Maps, Bodyscapes », in Sumathi Ramaswamy (éd.), Beyond Appearances? Visual Practices and Ideologies in Mondern India. Delhi, Sage : 157-195.

2006 « Enshrining the Map of India: Cartography, Nationalism, and the Politics of Deity in Varanasi », in Martin Gaenszle et Jörg Gengnagel (éd.), Visualizing Space in Banaras. Images, Maps, and the Practice of Representation Wiesbaden, Harrassowitz Verlag : 164-188.

RIVIÈRE, Georges-Henri et LEROUX-DHuYs, Jean-François

1991 «Musées et collections publiques », in Jean Poirier (éd.), Histoire des mœurs, vol. III. Paris, Gallimard : 185-218.

\section{SAVARKAR, Vinayak Damodar}

1964 Hindu Rashtra Darshan. Pune, Maharashtra Prantik Hindusabha.

\section{SingH, Rana P.B.}

1988 « The image of Varanasi: Sacrality and Perceptual World in Hindu Codification », The National Geographical Journal of India 34 : 1-32.

\section{VAN DER VEER, Peter \\ 1994 «Hindu "Nationalism" and the discourses of "Modernity" » in Martin E. Marty et R. Scott Appleby [éd.], Accounting for Fundamentalisms. Chicago, University of Chicago Press : 653-668. \\ VIDYARTHI, Lalita Prasad, MAKHAN, Jha et SARASWATI, B.N. \\ 1979 The Sacred Complex of Kashi: A Microcosm of Indian Civilization. Delhi, Concept Publishing Company.}

\section{Résumé / Abstract}

Mathieu Claveyrolas, Les temples de la Mère Inde, musées de la nation. - Le temple Bharat Mata de Bénarès, en Inde du Nord, est dédié à Mère Inde ; il propose comme image « divine » une carte en relief du territoire indien. Étudier ce temple moderne, inauguré en 1936 par Gandhi, permet d'analyser l'ambiguïté d'un lieu qui hésite entre le statut de musée dédié à la nation indienne séculière et celui de temple à la nation hindoue divinisée. Temple-musée que des pèlerins touristes visitent sans émotion ni dévotion véritable, le Bharat Mata pose la question des liens entre religion, histoire et politique, et de leur évolution, ainsi que des réactions pratiques locales à ces lieux au service de différentes rhétoriques nationalistes.
Mathieu Claveyrolas, The temples of "Mother India", museums of the nation. - The Bharat Mata temple of Benares, in northern India, is dedicated to "Mother India"; it houses a "divine" image in the form of a relief map of Indian territory. The study of this modern temple, inaugurated in 1936 by Gandhi, allows the analysis of the ambiguity of a place which lingers between the status of a museum dedicated to the secular Indian nation, and that of a temple to the Hindu nation divine. As a templemuseum which the pilgrim-tourists visit without real emotion or devotion, the Bharat Mata raises questions about the links between religion, history and politics, and their evolution, as well as about the practical reactions of local people to this place at the service of different nationalist rhetorics. 